\title{
Scanning by DOVAM-S Detects All Unique Sequence Changes in Blinded Analyses: Evidence that the Scanning Conditions Are Generic
}

BioTechniques 28:746-753 (April 2000)

C.H. Buzin, C.Y. Wen, V.Q. Nguyen, G. Nozari, A. Mengos, X. Li, J.S. Chen, Q. Liu, R.A. Gatti ${ }^{1}$, F.K. Fujimura and S.S. Sommer

City of Hope National Medical

Center, Duarte and ${ }^{1}$ UCLA

School of Medicine, Los

Angeles, CA, USA polymorphisms (180 of which are unique) were detected in both analyses. For two, three and four joint conditions, the average detection frequency ranged from $77 \%-97 \%$, $91 \%-100 \%$ and $95 \%-100 \%$, respectively. For each of the genes, one mutation may have been missed if only four conditions were used. With DOVAM-S, approximately $500 \mathrm{~kb}$ of autosomal sequence can be scanned in five gels with virtually $100 \%$ detection of mutations within the scanned region. The detection of 180 out of 180 unique sequence changes implies that DOVAM-S detects at least $96.5 \%(\mathrm{P}=0.03)$ of mutations. Blinded analyses that detect 400 unique sequence changes are required to determine that a scanning method detects at least $98.5 \%$ of mutations.

\section{INTRODUCTION}

Complete scanning for mutations in large genes from genomic DNA has been a difficult task, particularly for single nucleotide substitutions. These genes often contain many exons of varying sizes separated by relatively long intronic regions. A wide variety of gene scanning methods, each with advantages and disadvantages, has been developed $(2,3)$. In a few large genes such as $B R C A 1$ and $B R C A 2$, complete sequencing of all exons and flanking intronic regions has been used to identify mutations $(4,17)$.

Single strand conformation polymorphism (SSCP) analysis is frequently used to detect mutations by abnormal electrophoretic migration of ssDNA fragments on nondenaturing gels (15). Although the method is simple and fast, the standard protocol does not detect all mutations, and the sensitivity may vary widely, depending on segment size and sequence context (10). In this laboratory, several hybrid SSCP mutation screening techniques (detection by SSCP combined with another method) have been developed to increase the sensitivity of SSCP by generating multiple mutation-containing fragments.

Dideoxyfingerprinting and bidirectional dideoxyfingerprinting, which combine SSCP with conventional Sanger dideoxy sequencing (10) or bidirectional cycle sequencing (6), can detect essentially all mutations in DNA segments less than $300 \mathrm{bp}$ and $300-600 \mathrm{bp}$, respectively. Restriction endonuclease fingerprinting, another hybrid mutation screening technique that detects virtually all mutations, combines SSCP with restriction endonuclease digestion to analyze DNA segments of 1-2 kb (11).

Each of these methods has disadvantages for the complete mutation scanning of genomic DNA from large genes. To use restriction endonuclease fingerprinting to full advantage, contiguous DNA segments of 1-2 kb need to be analyzed, but most of the exons in large genes are small (less than $300 \mathrm{bp}$ ) and separated by large introns (much greater than $1 \mathrm{~kb}$ ); thus, each small exon would have to be examined separately. Both dideoxy fingerprinting and bidirectional dideoxy fingerprinting can be used for mutation screening in large genes, but each exon generates many fragments, requires one lane per sample and cannot be easily multiplexed.

Denaturing HPLC has also been used to screen for mutations $(14,19)$ but requires optimization of conditions for 
analysis of each exon, as well as a large capital investment for the instrument. Although analysis of a single exon is rapid, this method analyzes exons sequentially and, in some cases, more than one temperature is required for analysis of a given exon. One blinded analysis detected all 55 mutations (13), while another showed a sensitivity of $91 \%$ (12).

Recently, we described [detection of virtually all mutations]-SSCP (DOVAM-S), a variation of SSCP that involves scanning multiple exons in a single lane under five different nondenaturing electrophoresis conditions. The sensitivity of SSCP, although suboptimal under each single condition, is vastly improved by the redundancy of five conditions and permits the detection of essentially all mutations (7). Typically, a $500 \mathrm{~kb}$ autosomal sequence $(250 \mathrm{~kb}$ genomic sequence from two chromosomes) is screened in five gels (100 kb net screened per gel).

DOVAM-S was optimized and tested in two blinded analyses using the human factor IX gene that spans $34 \mathrm{~kb}$ genomic DNA and contains a functional region of approximately $2.2 \mathrm{~kb}(7)$. In the factor IX gene, DOVAM-S identified singlebase substitutions (all categories of transitions and transversions), hemizygous or homozygous large (whole exon) deletions, as well as microinsertions and deletions. The sensitivity of mutation detection was found to be $100 \%$.

To determine whether the five electrophoretic conditions in DOVAM-S that were developed for the factor IX gene could be used successfully for larger genes, we examined the human factor VIII gene (spans $186 \mathrm{~kb}$ of chromosomal DNA and contains 26 exons) (5) and the human ataxia telangiectasia (ATM) gene, one of the largest known genes (spans $146 \mathrm{~kb}$ and contains 66 exons) (16). Like the factor IX gene, the factor VIII gene is located on the $\mathrm{X}$ chromosome and thus is hemizygous in males. The ATM gene on chromosome 11 is autosomal. The vast majority of coding exons in both genes are less than $300 \mathrm{bp}$ in length. The factor VIII gene also contains one large $3.1 \mathrm{~kb}$ exon. Many of the introns in both genes are very large (greater than $1 \mathrm{~kb}$ ), and mutations are widely scattered throughout each gene. In a prospective analysis of the factor VIII gene and a blinded analysis of the ATM gene, DOVAM-S detected all known mutations in the regions scanned.

\section{MATERIALS AND METHODS}

\section{Definition of Terms}

Sequence changes. Any change from the wild-type sequence, including mutations and polymorphisms. Deleterious mutations or polymorphisms are equally useful in assessing the sensitivity of DOVAM-S.

Unique sequence changes. Some mutations and many of the polymorphisms were identified in more than one sample; a few of the common polymorphisms were identified in many samples. For the purpose of determining which electrophoretic conditions detected a given sequence change, the number of unique sequence changes was used, counting each different sequence change only once, no matter how many times it was found.

Total number of sequence changes. All sequence changes. The excess over unique sequence changes is a measure of the consistency of detecting a sequence change.

Joint electrophoretic conditions. A set of two or more different electrophoretic conditions considered together. A mutation is detected in a set of joint conditions if it is detected in any one of the electrophoresis conditions in the set. For five different conditions, there are ten possible combinations (sets) of two conditions, ten sets of three conditions and five sets of four conditions.

\section{Samples and Genomic Regions Scanned}

Genomic DNA from 92 hemophilia A patients ( 89 males and 3 females) was prospectively analyzed for mutations in the human factor VIII gene. Samples had previously been screened for the common intron 22 inversion in factor VIII (9) and only those negative for the inversion were included in this analysis. For each sample, a total of $8.8 \mathrm{~kb}$ DNA was screened and included all exons and adjacent intronic splice site regions, as well as $355 \mathrm{bp}$ and $185 \mathrm{bp}$ in the $5^{\prime}$ untranslated and $3^{\prime}$ untranslated regions, 
Table 1. Sensitivity of Mutation Detection in Individual Nondenaturing Electrophoresis Conditions

\begin{tabular}{|c|c|c|c|c|c|c|c|}
\hline \multirow[b]{2}{*}{ Condition Name ${ }^{a}$} & \multirow[b]{2}{*}{ Matrix ${ }^{b}$} & \multirow[b]{2}{*}{ Bufferc } & \multirow[b]{2}{*}{ Additive } & \multirow[b]{2}{*}{ Temperature ${ }^{d}$} & \multicolumn{3}{|c|}{ Sensitivity (\%)e } \\
\hline & & & & & factor VIII & ATM & factor IXf \\
\hline PC-8 & PAGEplus & Capso & - & $8^{\circ} \mathrm{C}$ & 88 & 82 & 85 \\
\hline HTG-8 & HR 1000 & TBE & $2.5 \%$ glycerol & $8^{\circ} \mathrm{C}$ & 80 & 68 & 89 \\
\hline PT-RT & PAGEplus & Tri/Tri & - & RT & 84 & 50 & 68 \\
\hline PTG-RT & PAGEplus & TBE & $5 \%$ glycerol & RT & 84 & 68 & 85 \\
\hline HT-8 & HR 1000 & Tri/Tri & - & $8^{\circ} \mathrm{C}$ & 83 & 82 & 78 \\
\hline \multicolumn{8}{|c|}{$\begin{array}{l}\text { aEach electrophoresis condition was given a mnemonic name based on the first letters of the matrix, buffer and additive, } \\
\text { followed by a dash and the temperature. }\end{array}$} \\
\hline \multirow{3}{*}{\multicolumn{8}{|c|}{$\begin{array}{l}\text { bGel matrices were 10\% PAGEplus (AMRESCO, Solon, OH, USA) and 10\% HR } 1000 \text { (Genomyx, Foster City, CA, USA). } \\
\text { cCapso: } 30 \mathrm{mM} \text { Capso/ethanolamine, } \mathrm{pH} \text { 9.6; TBE: } 50 \mathrm{mM} \text { Tris/boric acid, } \mathrm{pH} 8.3 \text {; Tri/Tri: } 30 \mathrm{mM} \text { Tricine/triethanolamine, } \mathrm{pH} 7.9 \text {. } \\
\text { dRoom temperature (RT); } 8^{\circ} \mathrm{C} \text { : measured temperature of gel plate during electrophoresis in a } 4^{\circ} \mathrm{C} \text { cold room. }\end{array}$}} \\
\hline & & & & & & & \\
\hline & & & & & & & \\
\hline \multicolumn{8}{|c|}{$\begin{array}{l}\text { eThe percentage of mutations and polymorphisms detected in each individual electrophoresis condition is given. The } \\
\text { analysis is based on unique sequence changes in the ATM gene }(n=22) \text { and the factor VIII gene [ } n=76 \text {, including } \\
\text { two large deletions (del exon } 6 \text { and del exons 11-18)]. }\end{array}$} \\
\hline \multicolumn{8}{|c|}{$\begin{array}{l}\text { fThe blinded DOVAM-S analysis of mutations in the factor IX gene was carried out previously (7). The data were reanalyzed } \\
\text { ( } \mathrm{n}=82 \text { unique mutations) for consistency with the analysis of the other genes. Seventy-three of the } 82 \text { unique sequence } \\
\text { changes were single-base substitutions, and nine were deletions or insertions (including three large deletions of one or more } \\
\text { exons). }\end{array}$} \\
\hline
\end{tabular}

respectively. Forty-eight segments, ranging from 140-328 bp, were amplified and analyzed as described below.

Nineteen A-T patients were selected for blinded analysis of the ATM gene. Their DNA had been previously screened for ATM mutations by the protein truncation test (18) and conformation sensitive gel electrophoresis (Liang et al., manuscript in preparation). Samples were coded and blinded to all personnel involved in the DOVAM-S experiments. The code was broken after the sequence changes had been determined and confirmed. Using genomic DNA, $17.1 \mathrm{~kb}$ ATM sequence were scanned per sample, which included all translated exons (E4-65), adjacent intronic regions and 175 bp $5^{\prime}$ untranslated sequence in intron 3 and the beginning of exon 4 . Seventy segments that ranged in size from 166-367 bp were amplified and analyzed.

\section{PCR Amplification}

For analysis of both genes, each segment was individually amplified by PCR from genomic DNA and labeled with $\alpha-33$ P-dATP. Using a robotic device with an integrated thermal cycler
(ABI PRISM ${ }^{\mathrm{TM}}$ 877; PE Biosystems, Foster City, CA, USA)(7), as many as 384 separate reactions could be prepared automatically and run concomitantly. After amplification, labeled products from each patient sample were pooled automatically for DOVAM-S analysis to give three groups of $16 \mathrm{seg}$ ments each (factor VIII) or four groups of 17-18 segments each (ATM). A list of new primers designed for amplification of the factor VIII and the ATM genes can be obtained from the authors.

\section{Electrophoresis}

Products were first electrophoresed on a $6 \%$ acrylamide/7 $\mathrm{M}$ urea denaturing gel to identify any unamplified products and to detect small insertions and deletions. If a product was not amplified, reamplification was attempted. Regions reproducibly associated with the absence of a band on DOVAM-S (found in two factor VIII samples) were scored as deletions. For X-linked genes such as factor VIII and factor IX, male patients have only a single allele, and a large deletion of a complete exon would result in a lack of amplification. Because ATM is an autosomal gene and patients are mainly compound heterozygotes, large deletions of the second allele would be masked by a normal PCR product from the first allele and would not be detected by this method.

For DOVAM-S analysis, $1.5 \mu \mathrm{L}$ labeled PCR products combined in groups of 16 to 18 were electrophoresed under five different nondenaturing conditions in which gel matrix, buffer, temperature and additive were varied. The conditions chosen, which together were able to detect all mutations in a blinded analysis of the factor IX gene (7), are shown in Table 1 . In three conditions, $\mathrm{pK}$-matched buffers were used, providing higher voltage, current stability and less heat generation (8). Electrophoresis was carried out on a $50 \mathrm{~cm} \times 38 \mathrm{~cm} \times 0.4 \mathrm{~mm}$ sequencing cell (Sequi-Gen ${ }^{\circledR}$ GT, BioRad Laboratories, Hercules, CA, USA) at a constant power of 10-20 W for 13-17 $\mathrm{h}$ with the exception of condition PTG-RT (50-65 W for 10-14 h). Control lanes containing groups of three to four labeled products were included for purposes of correct segment identification. Complete analysis of 48 samples required 15 or 20 nondenaturing gels (three or four lanes per sample under 
Table 2. DOVAM-S Scanning from Genomic DNA in Three Human Genes

\begin{tabular}{|c|c|c|c|c|c|c|}
\hline Gene & $\begin{array}{c}\text { No. } \\
\text { Samples } \\
\text { Analyzed }\end{array}$ & $\begin{array}{c}\text { No. } \\
\text { Segments } \\
\text { Analyzed/Sample }\end{array}$ & $\begin{array}{c}\text { No. } \\
\text { Samples with } \\
\text { Sequence change }\end{array}$ & $\begin{array}{c}\text { Total } \\
\text { No. Sequence } \\
\text { Changesa }\end{array}$ & $\begin{array}{l}\text { No. Unique } \\
\text { Sequence } \\
\text { Changesb }^{\text {Chan }}\end{array}$ & $\begin{array}{c}\text { Sequence } \\
\text { Changes } \\
\text { Detected (\%)c }\end{array}$ \\
\hline factor VIII & 92 & 48 & 85 & 113 & 76 & 100 \\
\hline ATM $^{d}$ & 19 & 70 & 19 & 49 & 22 & 100 \\
\hline factor IXe & 84 & 15 & 84 & 88 & 82 & 100 \\
\hline Totals & 195 & 133 & 188 & 250 & 180 & 100 \\
\hline \multicolumn{7}{|c|}{$\begin{array}{l}\text { aAll sequence changes (mutations and polymorphisms) were counted each time they occurred. } \\
\text { bEach sequence change was counted only once, even though some were found in multiple samples. } \\
\text { cDetection of sequence changes in the DOVAM-S scanning region for each gene. } \\
\text { dOnly mutations/polymorphisms previously found in these samples are included in the blinded analysis. } \\
\text { Additional mutations/polymorphisms were also found in the samples (not shown). } \\
\text { eData reanalvzed (7) See Table } 1\end{array}$} \\
\hline
\end{tabular}

five electrophoretic conditions) for factor VIII and ATM, respectively.

\section{Gel Analysis and DNA Sequencing}

Following electrophoresis, gels were dried and exposed to BioMax ${ }^{\circledR}$ MR film (Eastman Kodak, Rochester, NY, USA). Autoradiographs were analyzed to determine mobility shifts or intensity differences in particular segments that were identified through a comparison with known amplified products in control lanes. Segments expected to contain a mutation were amplified from a dilution of the SSCP mixture and sequenced by fluorescence cycle sequencing on a DNA sequencer. Sequences were analyzed using Sequencher ${ }^{\mathrm{TM}}$ software (Gene Codes, Ann Arbor, MI, USA). All mutations were confirmed by reamplification from the original genomic DNA and sequencing in the opposite direction.

\section{RESULTS AND DISCUSSION}

\section{Detection of Sequence Changes by DOVAM-S}

Because this study analyzes the efficiency of DOVAM-S to detect sequence changes, individual mutations are not listed but are available from the authors. All types of sequence changes-single-base changes (missense, nonsense, transitions and transversions), microinsertions and deletions and splice mutations-were included.

Figure 1 shows a nondenaturing gel containing factor VIII samples that were electrophoresed under PT-RT, one of the five DOVAM-S conditions (Table 1). When all five electrophoretic conditions were analyzed, sequence changes were detected in 85 of the 92 factor VIII samples (Table 2). Presumptive causative mutations were found in 85 patients. A total of 113 sequence changes (76 unique) were found, including two common polymorphisms present 12 and 14 times. For the seven samples in which no sequence changes were found by DOVAM-S analysis, complete sequencing in both directions of all $26 \mathrm{ex}-$ ons and adjacent intronic regions was performed. No sequence changes were found in any of the seven samples. Samples without detectable mutations in the DOVAM-S analysis did not contain mutations when the direct sequence analysis was used.

Note that all PCR-based methods, including direct sequence analysis and DOVAM-S, cannot detect certain types of mutations, including large heterozygous deletions, duplications and inversions. A quantitative assay is currently being developed to detect some of these mutations. In addition, 5' and $3^{\prime}$ untranslated regions that were not screened could contain sequence changes that would not be detected by these experiments.

Nineteen samples from A-T patients, for whom sequence changes had previously been identified by protein truncation test and conformation sensitive gel electrophoresis, were screened in a blinded analysis by DOVAM-S. Forty-nine previously known sequence changes (22 were unique) including several polymorphisms, each detected in multiple samples, were identified (Table 2). All previously known sequence changes that were included in the DOVAM-S scanning regions were detected. Besides the previously known sequence changes in these samples, 31 additional changes were identified, 17 of which were unique (data not shown).

Sensitivities of individual SSCP electrophoretic conditions for the detection of the 76 unique factor VIII sequence changes ranged from $83 \%-$ $88 \%$. The highest sensitivity appeared in condition PC-8 (Table 1). A broader range of sensitivities for detection of the 22 unique ATM sequence changes was observed (50\%-82\%), with highest sensitivity in PC-8 and HT-8, as compared with the lowest in PT-RT. These are presented in comparison to those found previously in the factor IX gene (7). No false positives were found in either the factor VIII or ATM genes when certain pitfalls were avoided, including (i) each band in a lane must have a wild-type band in at least one of the 
adjacent lanes; (ii) to assess subtle shifts, lanes must be very close together and only high-quality wells should be used; and (iii) if one SSCP segment is subtly but clearly different from the adjacent normal segment, assume the sample contains a mutation until a high-quality sequence has been examined in both directions for every base (1). A clear fragment shift on a DOVAM-S gel always indicated a sequence change.

The majority of sequence changes were detected in more than one SSCP condition. For the factor VIII gene, $46 \%$ of the sequence changes were detectable in all five electrophoretic conditions and $80 \%$ showed mobility alterations in at least four conditions. An additional $20 \%$ of the sequence changes could be detected in only one, two or three conditions: only one sequence change was detectable in a single condition (HTG-8). Of the three sequence changes identified in only two conditions each, one was detected in each of four conditions (PC-8, PT-RT, PTG-RT and HT-8), and two were detected in condition HTG-8.

In contrast to the factor VIII and factor IX genes, fewer sequence changes in the ATM gene could be detected in all five conditions (only 23\%) or in at least four conditions (59\%). Most of the ATM sequence changes were heterozygous and were more difficult to detect compared to the hemizygous mutations in the factor VIII and factor IX genes. In only one or two conditions, $18 \%$ of the sequence changes caused mobility shifts. The one sequence change detected in two conditions was found in PC-8 and HT- 8 . The three sequence changes identified in only one condition were each detected in a different condition (HTG-8, PT-RT and HT-8). This can be compared with the results previously found for the factor IX gene, in which six sequence changes were identified in only one condition (four in HTG-8, one in PC-8 and one in PTG-RT) (7). The redundancy of the DOVAM-S method is clearly necessary for the complete detection of ATM sequence changes.

The sensitivity of detection was decreased if fewer electrophoretic conditions were used in DOVAM-S analysis (Table 3). If joint combinations of all possible sets of two, three or four con-

Table 3. Sensitivity of Detection of Sequence Changes in All Possible Combinations of Electrophoresis Conditions

\begin{tabular}{|c|c|c|c|c|}
\hline \multirow[t]{2}{*}{ Gene $^{a}$} & \multicolumn{4}{|c|}{$\begin{array}{l}\text { No. of joint conditions: Percent of sequence } \\
\text { changes detected (number of sets }{ }^{b} \text { ) }\end{array}$} \\
\hline & 2 & 3 & 4 & 5 \\
\hline \multirow[t]{3}{*}{ factor VIII } & 97 (5) & 100 & 100 & 100 \\
\hline & $96(4)$ & 99 (3) & 99 (1) & \\
\hline & 95 (1) & 97 (2) & & \\
\hline \multirow[t]{5}{*}{ ATM } & $95(2)$ & 100 & 100 & 100 \\
\hline & 91 (3) & 95 (5) & 95 (3) & \\
\hline & 86 (3) & 91 (4) & & \\
\hline & $82(1)$ & & & \\
\hline & 77 (1) & & & \\
\hline \multicolumn{5}{|c|}{$\begin{array}{l}\text { aResults for the factor IX gene are given in Liu et al. (7). } \\
\text { bFor all combinations of nondenaturing gel electrophoresis conditions, there are } \\
10 \text { possible sets of two conditions, } 10 \text { sets of three conditions, five sets of four } \\
\text { conditions and one set of five conditions. See Table } 1 \text { for detection of sequence } \\
\text { changes in each individual condition. }\end{array}$} \\
\hline
\end{tabular}

ditions were considered, all sequence changes could be detected in certain sets of three or four conditions. However, with other combinations of conditions, at least one sequence change for each gene would be missed. For two, three and four joint electrophoretic con- ditions, the detection frequency ranged from $77 \%-97 \%, 91 \%-100 \%$ and $95 \%-$ $100 \%$, respectively. The sensitivity varies from segment to segment and gene to gene, making it hard to estimate the sensitivity of any set of one to four conditions. The $100 \%$ sensitivity

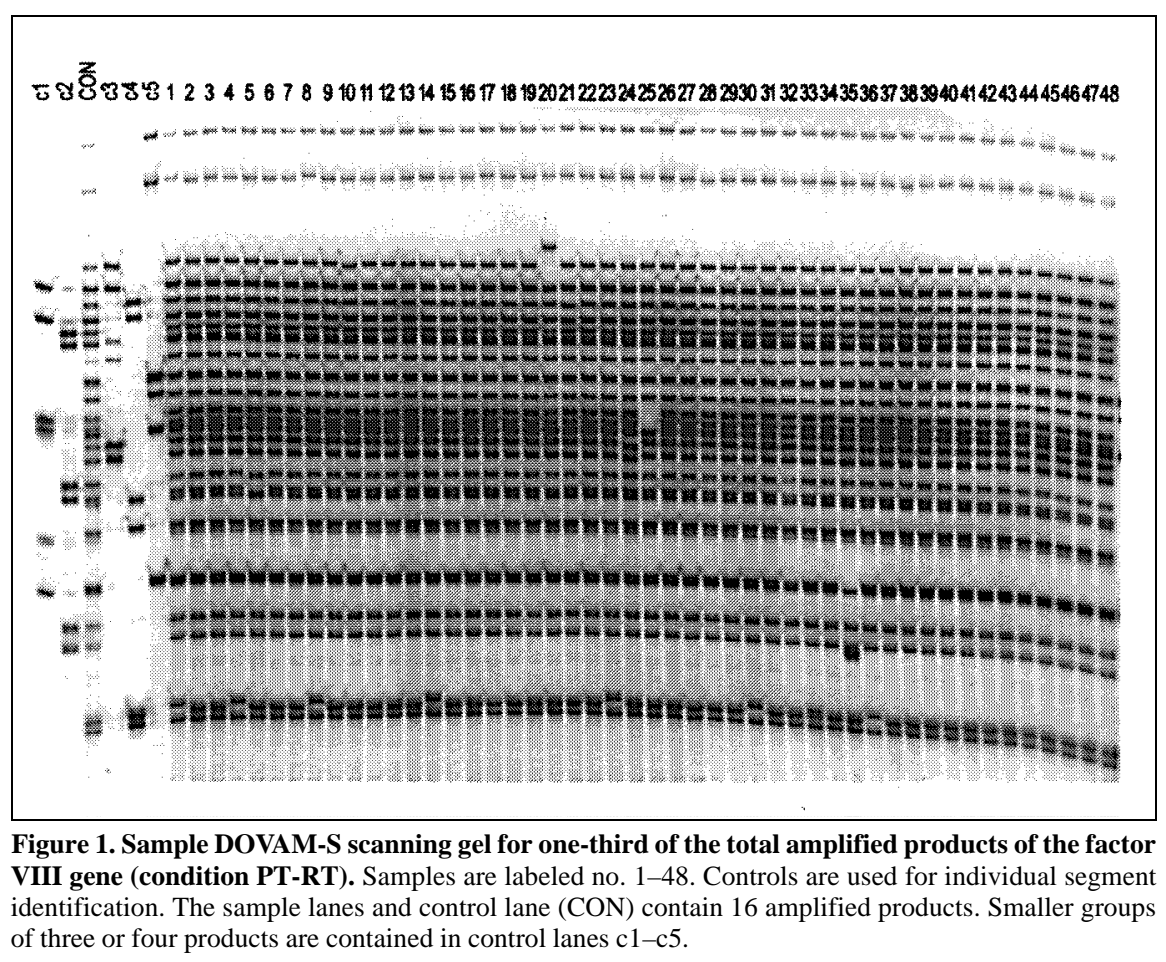


achieved with SSCP is dependent upon the five-condition DOVAM-S format.

DOVAM-S analysis has now been used to scan three human genes (factor VIII, ATM and factor IX) (7) of different sizes and numbers of exons. A total of 195 samples has been analyzed and 250 sequence changes (180 were unique) have been detected (Table 2). In blinded analyses, all of the known sequence changes within the scanning region were detected: 88 total and 82 unique in the factor IX gene (7) and 49 total and 22 unique in the ATM gene. The factor VIII prospective analysis detected mutations in all but seven samples, which were shown by direct sequence analysis not to contain a mutation in the regions scanned. The strongest advantages of the DOVAM-S method include the parallel analysis of 45-50 samples using multiple amplified products per gel lane, and the increase in sensitivity of mutation detection to approximately $100 \%$ provided by the redundancy of the five different electrophoretic conditions. DOVAM-S is a robust method for scanning genomic DNA, particularly in large genes with widely separated exons and mutations scattered throughout the gene.

Designing the most effective strategy for detecting unknown mutations in a gene will be determined by the efficiency levels reported herein and also by (i) the size of the gene, (ii) the types of mutations, (iii) the availability of other methods and (iv) the number of patients to be studied.

\section{ACKNOWLEDGMENTS}

We thank Dr. Jing-zhong Liu for the design of primers used in the factor VIII PCRs and Ms. Wenyan Li for expert ABI sequencing. This work was supported in part by a grant from the A-T Medical Research Foundation (Los Angeles, CA, USA) to Dr. S.S. Sommer.

\section{REFERENCES}

1.Blaszyk H., A. Hartmann, J.J. Schroeder, R.M. McGovern, S.S. Sommer and J.S. Kovach. 1995. Rapid and efficient screening for p53 gene mutations by dideoxy fingerprinting (ddF). BioTechniques 18:256-260.

2.Cotton, R.G. 1993. Current methods of muta- tion detection. Mutat. Res. 285:125-144.

3.Cotton, R.G.H., E. Edkins and S. Forrest. 1998. Mutation Detection. Oxford University Press, New York.

4.Frank, T.S., S.A. Manley, O.I. Olopade, S. Cummings, J.E. Garber, B. Bernhardt, K. Antman, D. Russo et al. 1998. Sequence analysis of BRCA1 and BRCA2: correlation of mutations with family history and ovarian cancer risk. J. Clin. Oncol. 16:2417-2425.

5.Gitschier, J., W.I. Wood, T.M. Goralka, K.L. Wion, E.Y. Chen, D.H. Eaton, G.A. Vehar, D.J. Capon and R.M. Lawn. 1984. Characterization of the human factor VIII gene. Nature 312:326-330.

6.Haavik, J., H. Nishino, Q. Liu and S.S. Sommer. 1996. Bidirectional dideoxy fingerprinting (Bi-ddF): rapid and efficient screening for mutations in the Big Blue transgenic mouse mutation detection system. BioTechniques 20:988-994.

7.Liu, Q., J. Feng, C. Buzin, C. Wen, G. Nozari, A. Mengos, V. Nguyen, J.-Z. Liu et al. 1999. Detection of virtually all mutationsSSCP (DOVAM-S): a rapid method for mutation scanning with virtually $100 \%$ sensitivity. BioTechniques 26:932-942.

8.Liu, Q., X. Li and S.S. Sommer. 1999. pKmatched running buffers for gel electrophoresis. Anal. Biochem. 270:112-122.

9.Liu, Q., G. Nozari and S.S. Sommer. 1998. Single-tube polymerase chain reaction for rapid diagnosis of the inversion hotspot of mutation in hemophilia A. Blood 92:1458-1459.

10.Liu, Q. and S.S. Sommer. 1994. Parameters affecting the sensitivities of dideoxy fingerprinting and SSCP. PCR Methods App. 4:97108.

11.Liu, Q. and S.S. Sommer. 1995. Restriction endonuclease fingerprinting (REF): a sensitive method for screening mutations in long, contiguous segments of DNA. BioTechniques 18:470-477.

12.Liu, W., D.I. Smith, K.J. Rechtzigel, S.N. Thibodeau and C.D. James. 1998. Denaturing high performance liquid chromatography (DHPLC) used in the detection of germline and somatic mutations. Nucleic Acids Res. 26:1396-1400.

13.O'Donovan, M.C., P.J. Oefner, S.C. Roberts, J. Austin, B. Hoogendoorn, C. Guy, G. Speight, M. Upadhyaya et al. 1998. Blind analysis of denaturing high-performance liquid chromatography as a tool for mutation detection. Genomics 52:44-49.

14.Oefner, P. and P. Underhill. 1998. DNA mutation detection using denaturing high-performance liquid chromatography (DHPLC). Current Protocols in Human Genetics Supplement 19:7.10.1-7.10.12.

15.Orita, M., H. Iwahana, H. Kanazawa, K. Hayashi and T. Sekiya. 1989. Detection of polymorphisms of human DNA by gel electrophoresis as single-strand conformation polymorphisms. Proc. Natl. Acad. Sci. USA 86:2766-2770.

16.Platzer, M., G. Rotman, D. Bauer, T. Uziel, K. Savitsky, A. Bar-Shira, S. Gilad, Y. Shiloh and A. Rosenthal. 1997. Ataxiatelangiectasia locus: sequence analysis of 184 $\mathrm{kb}$ of human genomic DNA containing the entire ATM gene. Genome Res. 7:592-605.
17.Shattuck-Eidens, D., A. Oliphant, M. McClure, C. McBride, J. Gupte, T. Rubano, D. Pruss, S.V. Tavtigian et al. 1997. BRCA1 sequence analysis in women at high risk for susceptibility mutations. JAMA 278:1242-1250.

18.Telatar, M., Z. Wang, N. Udar, T. Liang, E. Bernatowska-Matuszkiewicz, M. Lavin, Y. Shiloh, P. Concannon et al. 1996. Ataxiatelangiectasia: mutations in ATM cDNA detected by protein-truncation screening. Am. J. Hum. Genet. 59:40-44.

19.Underhill, P.A., L. Jin, A.A. Lin, S.Q. Mehdi, T. Jenkins, D. Vollrath, R.W. Davis, L.L. Cavalli-Sforza and P.J. Oefner. 1997. Detection of numerous $\mathrm{Y}$ chromosome biallelic polymorphisms by denaturing high-performance liquid chromatography (DHPLC). Genome Res. 7:996-1005.

Received 3 August 1999; accepted 30 November 1999.

Address correspondence to:

Dr. Steve S. Sommer

Departments of Molecular Genetics and Molecular Diagnosis

City of Hope National Medical Center

1500 East Duarte Road

Duarte, CA 91010-3000, USA

Internet: ssommer@coh.org 